\title{
Prevalence of the Metabolic Syndrome among North Indian Adolescents Using Adult Treatment Panel III and Pediatric International Diabetic Federation Definitions
}

\section{Riyaz A Bhat ${ }^{1 *}$, Irshad Parray ${ }^{2}$ and Zeeshan Ahmad}

${ }^{1}$ Noora Multispecialty Hospital, Srinagar, Kashmir, India

${ }^{2}$ Sheri Kashmir Institute of Medical Sciences, Kashmir, India

\begin{abstract}
Background: Childhood obesity is an important risk factor for the development of metabolic syndrome in children and adolescent. Because of high prevalence of Insulin resistance and metabolic syndrome in Indian Adult population, studies are needed to identify the prevalence of these metabolic abnormalities in adolescent population.
\end{abstract}

Aim: The aim of this study was to estimate the prevalence of metabolic syndrome using Pediatric International Diabetic Federation definition and compare it with estimates of Adult Treatment Panel III definition among adolescents in Northern India.

Material and methods: At total of 899 adolescents attending school (aged 10-18 years) participated in this population-based prospective study. All the clinical and biochemical assessment was done after proper consent. The metabolic syndrome was determined by the National Cholesterol Education Program Adult Treatment Panel III definition modified for age and Pediatric international diabetic federation definition.

Results: The prevalence of metabolic syndrome was 3.5\% according to Adult Treatment Panel III criteria and $1.5 \%$ based on International Diabetic Federation criteria. No significant gender difference was observed in the distribution of metabolic syndrome. Hypertriglyceridemia was the most common and abdominal obesity the least common constituent of metabolic syndrome.

Conclusion: This study provides the first estimates of metabolic syndrome using pediatric international diabetic federation definition in adolescent population from northern India.

Keywords: Metabolic syndrome; Waist circumference; Dyslipidemia

\section{Introduction}

Insulin resistance syndrome was first described by Reaven [1] as the concomitant presence of abdominal adiposity, dyslipidemia, hypertension and insulin resistance or type 2 diabetes mellitus and described this syndrome complex as syndrome X. Although researchers coined different terms to this syndrome complex [2,3], the term metabolic syndrome (MS) was coined by Adult Treatment Panel III -National Cholesterol Education Program (ATPIII-NCEP) to use a common definition in the global context and consider other causal factors related with abdominal fat excess [4].

Childhood obesity is an important risk factor for the development of MS in children and adolescents [5]. MS in children and adolescents has been linked to hostile intrauterine environment leading to intrauterine growth retardation, low birth weight and small for gestational age $[6,7]$. Other factors can be genetic, socio-economic, environmental (obesogenic environment), urbanization, unhealthy diet and increasingly sedentary lifestyle [8,9]. Obese children with metabolic syndrome are at increasing risk of progressing to type 2 diabetes and cardiovascular disease in later life [10]. Early identification of children at risk and preventive action are therefore very important. However, to date, no unified definition exists to assess risk or outcomes in children and adolescents, and existing adult-based definitions of the metabolic syndrome are not appropriate to address the problem in this age group. This disagreement in proposing a unified definition mainly results from the difficulty in establishing cutoff points due to the absence of clinical manifestations of cardiovascular diseases in childhood [11]. There are doubts whether cutoff points must be absolute or expressed in percentiles considering age, gender and pubertal stage due to rapid growth in childhood and mainly in adolescence [12]. Lately, International diabetic federation (IDF) proposed a consensus definition of MS for children and adolescents so as to obtain a universally accepted tool which is easy to use for the early diagnosis. This will also help us to take preventive measures before the child or adolescent develops diabetes or cardiovascular disease, thus becoming the major organization to do so [10].

Different studies have shown varied prevalence of MS using different cutoffs and criteria. In the third National Health and Nutrition Examination Survey (NHANES III) conducted between 1988 and 1994, the prevalence of MS was 6.8 percent among overweight adolescents and 28.7 percent among obese adolescents [13].

Studies from south Asian children including India have shown high prevalence of MS. This could be attributed to the high level of insulin

*Corresponding author: Riyaz Ahmad Bhat, Noora Multispecialty Hospital, Shaltang, HMT Srinagar, Kashmir, India, Tel: 9419604468; E-mail: bhatdrriaz@hotmail.com

Received November 07, 2013; Accepted March 06, 2014; Published March 10 2014

Citation: Bhat RA, Parray I, Ahmad Z (2014) Prevalence of the Metabolic Syndrome among North Indian Adolescents Using Adult Treatment Panel III and Pediatric International Diabetic Federation Definitions. J Diabetes Metab 5: 352 doi:10.4172/2155-6156.1000352

Copyright: @ 2014 Bhat RA, et al. This is an open-access article distributed under the terms of the Creative Commons Attribution License, which permits unrestricted use, distribution, and reproduction in any medium, provided the original author and source are credited. 
Citation: Bhat RA, Parray I, Ahmad Z (2014) Prevalence of the Metabolic Syndrome among North Indian Adolescents Using Adult Treatment Panel III and Pediatric International Diabetic Federation Definitions. J Diabetes Metab 5: 352. doi:10.4172/2155-6156.1000352

resistance among them [14]. Also the relation between adiposity and insulin concentrations is stronger in South Asian children than among White Caucasian children [12]. South Asian children have higher mean fasting levels of insulin and fasting blood glucose and a higher prevalence of impaired fasting glucose than European Caucasians $[15,16]$. Although limited, studies from north India have shown high prevalence of MS like other south Asian studies [17,18]. The prevalence estimates of MS using IDF definition are not available from India. We therefore analyzed data according to ATP III definition of metabolic MS, examined its demographic variation and estimated the prevalence according to IDF definition which happens to be the latest organized definition [10] in the northern Indian state of Kashmir

\section{Material and Methods}

\section{Study design}

This cross sectional population based study was carried out in a representative sample of 889 children aged 10-18 years selected from different schools. The study was conducted in a multistage manner over a period of 2 years (October, 2009- October, 2011) among children selected by a simple randomization method. There are total 6 towns amongst which four are major and urbanized. There are approximately five to eight schools in each town. Four schools with enrollment more than 1000 were selected from four major towns. All the schools selected were of equal standard with almost equal children population and distribution. From each school, following children were selected in first phase. a) Children aged 10-18 yrs. (b) Children who had consent from parents. (c) Children who were not suffering from any metabolic disease. (d) Children not on any medication in any form. A total of 1100 children (in all the four schools) were selected in this stage. These children were selected by simple randomization. The sample size for the study was calculated from the formula given by Daniel WW. This formula is based on the assumption of normal approximation.

Finally 889 children turned up for the study. The Study was approved by ethical committee Sheri-Kashmir institute of medical sciences, Srinagar Kashmir; Director Education Kashmir and a proper approval from respective institutional bodies were obtained. The consent from the parents of children for examination and blood sampling was taken after explaining to them the purpose of study. A team consisting of 2-3 doctors, a nurse, lab technician and a helper visited each individual school on prefixed dates.

\section{Sampling method and biochemical measurements}

Children were asked to come fasting on the day of sampling $(\geq 8$ hrs fast). About $10 \mathrm{ml}$ non-heparinised venous blood samples were drawn from non-dominant arm without using tourniquet. Serum was separated within 2 hours of venipuncture, and analysis was done within $24 \mathrm{~h}$. Biochemical parameters were analyzed with commercially available enzymatic reagents (Audit Diagnostics, Ireland) adapted to the Hitachi 912 auto analyzer.

\section{Anthropometric measurements}

All subjects underwent anthropometric assessment like measurement of height, weight, Body mass index (BMI), waist circumference (WC) and measurement of blood pressure. Body weight was measured by an electronic scale $\left(\right.$ Filizola $^{\circledR}$ ) to the nearest $0.1 \mathrm{~kg}$ while the school children were barefoot and wearing light clothes. Height was determined by a portable Seca ${ }^{\circledR}$ stadiometer to the nearest 01.cm, according to norms proposed by the World Health Organization (WHO, 1995) [3]. BMI (weight in kilograms divided by the squared height in meters) was calculated by using the measured height and weight and converted to percentiles for age in months and gender by using the Center for Disease Control and Prevention (CDC, 2000) growth charts and computer software Epi-Info ${ }^{\circledR}$ version 3.2 (2004) [19]. Indian BMI Percentiles were used to classify children in different classes [20]. WC was measured midway between the rib cage and the superior border of the iliac crest by using a milli-metric non-extensible and nonelastic measuring tape $\left(\right.$ Sanny $\left.^{\mathbb{R}}\right)$ in midrespiration and inferences were drawn in percentiles.

Blood pressure was measured by the mercury sphygmomanometer method after the child had been sitting at rest for a minimum period of 5 minutes, and the cuff involved $80 \%$ of the right arm's circumference. The arm rested on a support surface at the level of the precordium. Three variable cuff sizes were used according to the child's brachial circumference. Blood pressure was measured three times in three different days only when the first measurement was above 95th percentile according to gender, age and height, based on The Fourth Report on the Diagnosis, Evaluation, and Treatment of High Blood Pressure in Children and Adolescents [21].

\section{Definitions of MS}

Metabolic syndrome was defined using modified ATPIII criteria $[3,22,23]$ as well as IDF criteria [10] and the results were compared with each other.

ATPIII criteria modified for age defines the presence of metabolic syndrome when three of the following criteria are met: (1) Triglycerides $\geq 110 \mathrm{mg} / \mathrm{dl}$ (2) High density lipoprotein cholesterol (HDL-C) $\leq 40$ $\mathrm{mg} / \mathrm{dl}$ (3) Systolic blood pressure or diastolic blood pressure $\geq 90^{\text {th }}$ percentile for age and gender (4) WC $\geq 90^{\text {th }}$ percentile for age and gender (5) Fasting blood glucose $\geq 110$ [24].

According to the IDF definition, an individual aged $10-16$ years has the metabolic syndrome if he or she has central adiposity ( $\geq 90$ th waist circumference percentile or adult threshold if lower) plus at least two of the following criteria: (1) triglycerides $\geq 150 \mathrm{mg} / \mathrm{dl}$ (2) HDL-C $<40 \mathrm{mg} /$ $\mathrm{dl}$ (3) systolic blood pressure $\geq 130 \mathrm{mmHg}$ or diastolic blood pressure $\geq 85 \mathrm{mmHg}$ (4) fasting plasma glucose $\geq 100 \mathrm{mg} / \mathrm{dl}$ or previously diagnosed type 2 diabetes. For those aged $\geq 16$ years, the adult IDF definition of the metabolic syndrome was applied [25].

\section{Statistical analysis}

Data were analyzed by SPSS 11.5 version. The prevalence was reported in percentages. Factor analysis and inference were drawn using chi-square test for proportions and Man Whitney $U$ test for comparison of independent groups. A two-tailed $P$ value was used for calculating statistical significance. A $p$ value of $<0.05$ was taken as statistically significant.

\section{Results}

Out of total 1100 children, 899 children turned up for the study. The sample population of 899 children and adolescents was a heterogeneous population and consisted of 311 males and 588 females. Their mean age was $13.4 \pm 3.8$. The characteristics of the subjects are shown in Table 1 .

According to ATP III criteria, 3.5\% children aged 10-18 years had MS whereas $1.5 \%$ children of similar age group had MS according to IDF criteria (Table 2). The prevalence of metabolic syndrome in males vs. females was statistically insignificant in both criteria. Factor analysis according ATPIII criteria showed that hypertriglyceridemia was most prevalent factor followed by low HDL cholesterol, 
Citation: Bhat RA, Parray I, Ahmad Z (2014) Prevalence of the Metabolic Syndrome among North Indian Adolescents Using Adult Treatment Panel III and Pediatric International Diabetic Federation Definitions. J Diabetes Metab 5: 352. doi:10.4172/2155-6156.1000352

Page 3 of 4

hyperglycemia, hypertension, and waist circumference. Among these factors hypertriglyceridemia and hyperglycemia showed statistically significant difference between two sexes (Table 2).

In both criteria, high prevalence of MS was seen in age group 13-15 years and the difference across different age groups was significant in ATPIII criteria. All metabolic parameters except high blood sugar were highly prevalent in the same age group which corresponds to puberty age. Again abdominal obesity, blood pressure and hyperglycemia showed statistically significant difference across different age groups (Table 2).

\section{Discussion}

This study could be the first study from India which used recently proposed pediatric IDF definition for evaluating the prevalence of MS and compared it with estimates of ATPIII criteria. Like its adult definition, the pediatric definition emphasizes the central role of obesity. Studies across the world have shown different prevalence estimates owning to lack of use of uniform definitions in their studies $[26,27]$.

Low prevalence of MS was observed when IDF definition was applied, which could be due to the fact that the IDF retained the adult cut points of its adult definition [10]. ATPIII uses lower cutoffs for blood pressure and triglyceride levels. Data from India though limited

\begin{tabular}{|l|c|c|c|c|}
\hline Parameters & Male (N- 311) & Female (N- 558) & Total (N- 869) & $P$ Value \\
\hline Age (years) & $11.06 \pm 2.7$ & $15.39 \pm 3.5$ & $13.45 \pm 3.8$ & 0.10 \\
\hline $\begin{array}{l}\text { Systolic blood } \\
\text { pressure (mm/Hg) }\end{array}$ & $103.41 \pm 8.2$ & $108.07 \pm 11.3$ & $105 \pm 10.3$ & 0.09 \\
\hline $\begin{array}{l}\text { Diastolic blood } \\
\text { pressure (mm/Hg) }\end{array}$ & $66.34 \pm 5.9$ & $71.37 \pm 7.7$ & $69.11 \pm 7.4$ & 0.09 \\
\hline $\begin{array}{l}\text { Waist circumference } \\
\text { (cm) }\end{array}$ & $55.69 \pm 12.2$ & $70.47 \pm 11.4$ & $63.84 \pm 13.9$ & .01 \\
\hline $\begin{array}{l}\text { Fasting blood glucose } \\
\text { (mmol/L) }\end{array}$ & $4.70 \pm 0.71$ & $4.76 \pm 0.52$ & $4.73 \pm 0.62$ & 0.59 \\
\hline Triglycerides (mmol/L) & $1.34 \pm 0.32$ & $1.38 \pm 0.41$ & $1.36 \pm 0.37$ & 0.50 \\
\hline $\begin{array}{l}\text { HDL-cholesterol } \\
\text { (mmol/L) }\end{array}$ & $1.06 \pm 0.12$ & $1.08 \pm 0.14$ & $1.07 \pm 0.13$ & 0.30 \\
\hline BMl (CDC) $\left(\mathrm{kg} / \mathrm{m}^{2}\right)$ & $18 \pm 2.1$ & $23.2 \pm 2.3$ & $20.7 \pm 2.0$ & 0.04 \\
\hline Weight & $41.5 \pm 8.7$ & $45 \pm 9.4$ & $43.5 \pm 8.6$ & 1.0 \\
\hline
\end{tabular}

Table 1: Clinical and Laboratory characteristics of the sample. has shown prevalence in non obese children ranging from $0.8 \%$ to $5 \%$ $[17,18]$. The prevalence of MS in non obese children in our study is alarming and needs attention.

Friend et al. [28] did a systematic review of different databases, collected details of overall prevalence and prevalence within groups categorized by obesity, gender, age, and ethnicity. This study was conducted in Scotland. The median prevalence of metabolic syndrome in whole populations was 3.3\% (range 0\%-19.2\%), in overweight children was $11.9 \%$ (range $2.8 \%-29.3 \%$ ), and in obese populations was $29.2 \%$ (range 10\%-66\%). Within-study analyses confirmed higher prevalence for obese compared to overweight $(\mathrm{P}=0.012)$ and obese compared to nonobese, nonoverweight children $(\mathrm{P}<0.001)$. Withinstudy analyses also revealed higher median metabolic syndrome prevalence for boys compared to girls $(5.1 \%$ versus $3.0 \%, \mathrm{P}<0.001)$ and also in older compared with younger children (5.6\% versus $2.9 \%$, $\mathrm{P}=0.001$ ) [28]. Similarly a study from Tailor et al. showed that the prevalence estimates from general population and community-based sampling ranged from $1.2 \%$ to $22.6 \%$ with rates of up to $60 \%$ observed in the overweight and obese [29].

According to Barker's Hypothesis, there is a links between reduced birthweight and increased risk of coronary heart disease, diabetes, hypertension and stroke in adulthood [30]. A systematic review reported that the majority of 80 studies on adults and children showed that there is a $2-\mathrm{mmHg}$ decrease in systolic blood pressure per kilogram increase in birthweight [31]. This relationship is less well defined in adolescence, possibly because 'tracking' of blood pressure with age is disturbed at the time of the adolescent growth spurt.

Maximum prevalence (6.8\% with ATP and $2.7 \%$ with IDF) was seen around the puberty (defined by age and not evidenced clinically or biochemically). No statistically significant difference was seen between two sexes although significant differences were observed across age groups. The effects of obesity on early puberty development have been shown though not conclusively established [32,33]. However, effects of puberty on obesity are not known. Normal puberty in girls is accompanied by increases in BMI and subcutaneous adiposity [29]. Also lipid abnormalities, particularly in males, are affected by puberty [34]. Whether these normal physiological processes have any significance in the development of obesity and MS around puberty in susceptible persons needs further elucidation.

\begin{tabular}{|c|c|c|c|c|c|c|c|c|}
\hline & $\begin{array}{l}\text { Sample } \\
\text { size }(n)\end{array}$ & $\begin{array}{l}\text { Metabolic } \\
\text { syndrome* }\end{array}$ & $\begin{array}{c}\text { Metabolic } \\
\text { syndrome }^{\star *}\end{array}$ & Abdominal obesity\# & Hypertriglyceridemia\# & $\begin{array}{c}\text { Low HDL } \\
\text { cholesterol\# }\end{array}$ & $\begin{array}{l}\text { High blood } \\
\text { pressure\# }\end{array}$ & Hyperglycemia\# \\
\hline $\begin{array}{l}\text { Total } \\
\text { participants }\end{array}$ & 899 & $3.60 \%$ & $1.50 \%$ & $3.70 \%$ & $31 \%$ & $17 \%$ & $4 \%$ & $9.80 \%$ \\
\hline \multicolumn{9}{|l|}{ Age (years) } \\
\hline 12-Oct & 218 & $2.70 \%$ & $0.40 \%$ & $4.70 \%$ & $33 \%$ & $17 \%$ & $2.80 \%$ & $18.80 \%$ \\
\hline $13-15$ & 219 & $6.80 \%$ & $2.70 \%$ & $10.00 \%$ & $27.40 \%$ & $21.90 \%$ & $7.80 \%$ & $13.60 \%$ \\
\hline $16-18$ & 462 & $2.50 \%$ & $1.50 \%$ & $6 \%$ & $32.10 \%$ & $17.20 \%$ & $4.50 \%$ & $3.40 \%$ \\
\hline $\mathrm{P}$ for linear trend & & 0.01 & 0.08 & 0.04 & 0.9 & 0.1 & 0.03 & 0.01 \\
\hline \multicolumn{9}{|l|}{ Sex } \\
\hline Male & 311 & $3.80 \%$ & $1.90 \%$ & $3 \%$ & $26 \%$ & $18 \%$ & $4 \%$ & $12 \%$ \\
\hline Female & 588 & $3.50 \%$ & $1.30 \%$ & $4 \%$ & $35 \%$ & $16 \%$ & $3.80 \%$ & $5 \%$ \\
\hline$P$ & & 0.69 & 0.12 & 0.2 & 0.03 & 1 & 1.01 & 0.02 \\
\hline
\end{tabular}

*Metabolic Syndrome (ATPIII criteria)

**Metabolic Syndrome (IDF criteria)

"Factor analysis (ATPIII criteria)

Table 2: Unadjusted prevalence of the metabolic syndrome and its components based on ATPIII criteria and pediatric criteria from the IDF among North Indian Adolescents aged $10-18$ years. 
Citation: Bhat RA, Parray I, Ahmad Z (2014) Prevalence of the Metabolic Syndrome among North Indian Adolescents Using Adult Treatment Panel III and Pediatric International Diabetic Federation Definitions. J Diabetes Metab 5: 352. doi:10.4172/2155-6156.1000352

Lipid abnormalities in the form of high triglyceride levels are the common abnormalities found in our study along different age groups. These observations are consistent with observations made in other south Asian studies [35]. Asian Indian population is highly insulin resistant even in the presence of only mild increase of BMI or abdominal adiposity [36]. Importantly, a higher level of hyperinsulinemia was reported in India neonates, as recorded at birth, compared with White Caucasian neonates [37].

\section{Conclusion}

This study provides the first estimates on the prevalence of MS with ATPIII and pediatric IDF definition in northern Indian Adolescent population. Both the definitions showed high prevalence around the age of puberty. Immediate lifestyle modifications are needed to control the obesity epidemic and its metabolic consequences. Furthermore, research is needed to know the effects of puberty on obesity and its late consequences.

\section{References}

1. Reaven GM (1988) Banting lecture 1988. Role of insulin resistance in human disease. Diabetes 37: 1595-1607.

2. Li Y, Yang X, Zhai F, Piao J, Zhao W, et al. (2008) Childhood obesity and its health consequence in China. Obes Rev 9: 82-86.

3. Cook S, Weitzman M, Auinger P, Nguyen M, Dietz WH (2003) Prevalence of a metabolic syndrome phenotype in adolescents: findings from the third National Health and Nutrition Examination Survey, 1988-1994. Arch Pediatr Adolesc Med 157: 821-827.

4. Strauss RS, Pollack HA (2001) Epidemic increase in childhood overweight, 1986-1998. JAMA 286: 2845-2848.

5. Burke V, Beilin LJ, Simmer K, Oddy WH, Blake KV, et al. (2005) Predictors of body mass index and associations with cardiovascular risk factors in Australian children: a prospective cohort study. Int J Obes (Lond) 29: 15-23.

6. Chatelain P (2000) Children born with intra-uterine growth retardation (IUGR) or small for gestational age (SGA): long term growth and metabolic consequences. Endocr Regul 34: 33-36.

7. Wei JN, Sung FC, Li CY, Chang CH, Lin RS, et al. (2003) Low birth weight and high birth weight infants are both at an increased risk to have type 2 diabetes among schoolchildren in taiwan. Diabetes Care 26: 343-348.

8. Bhowmik B, Afsana F, My Diep L, BinteMunir S, Wright E, et al. (2013) Increasing prevalence of type 2 diabetes in a rural Bangladeshi population: a population based study for 10 years. Diabetes Metab J 37: 46-53.

9. Alberti G, Zimmet P, Shaw J, Bloomgarden Z, Kaufman F, et al. (2004) Type 2 diabetes in the young: the evolving epidemic: the international diabetes federation consensus workshop. Diabetes Care 27: 1798-1811.

10. Zimmet P, Alberti KG, Kaufman F, Tajima N, Silink M, et al. (2007) The metabolic syndrome in children and adolescents - an IDF consensus report. Pediatr Diabetes 8: 299-306.

11. National High Blood Pressure Education Program Working Group on High Blood Pressure in Children and Adolescents (2004) The fourth report on the diagnosis, evaluation, and treatment of high blood pressure in children and adolescents. Pediatrics 114: 555-576.

12. Ten S, Maclaren N (2004) Insulin resistance syndrome in children. J Clin Endocrinol Metab 89: 2526-2539.

13. Park HS, Han JH, Choi KM, Kim SM (2005) Relation between elevated serum alanine aminotransferase and metabolic syndrome in Korean adolescents. Am J Clin Nutr 82: 1046-1051.

14. Whincup PH, Nightingale CM, Owen CG, Rudnicka AR, Gibb I, et al. (2010) Early emergence of ethnic differences in type 2 diabetes precursors in the UK: the Child Heart and Health Study in England (CHASE Study). PLoS Med 7: e1000263

15. Whincup PH, Gilg JA, Owen CG, Odoki K, Alberti KG, et al. (2005) British South Asians aged 13-16 years have higher fasting glucose and insulin levels than Europeans. Diabet Med 22: 1275-1277.
16. Wasir JS, Misra A (2007) The MS in Asain Indians; the impact of nutrition and socio-economic transition in India. MS related disorder 2004. Diabet Med 24: 195-199.

17. Singh R, Bhansali A, Sialy R, Aggarwal A (2007) Prevalence of metabolic syndrome in adolescents from a north Indian population. Diabet Med 24: 195-199.

18. Misra A, Khurana L, Vikram NK, Goel A, Wasir JS (2007) Metabolic syndrome in children: current issues and South Asian perspective. Nutrition 23: 895-910.

19. Zimmet P, Alberti G, Kaufman F, Tajima N, Silink M, et al. (2007) The metabolic syndrome in children and adolescents. Lancet 369: 2059-2061.

20. Kumar HN, Mohanan P, Kotian S, Sajjan BS, Kumar SG (2008) Prevalence of overweight and obesity among preschool children in semi urban South India. Indian Pediatr 45: 497-449.

21. Viner RM, Segal TY, Lichtarowicz-Krynska E, Hindmarsh P (2005) Prevalence of the insulin resistance syndrome in obesity. Arch Dis Child 90: 10-14.

22. Expert Panel on Detection, Evaluation, and Treatment of High Blood Cholesterol in Adults (2001) Executive Summary of the Third Report of the National Cholesterol Education Program (NCEP) Expert Panel on Detection, Evaluation, and Treatment of High Blood Cholesterol in Adults (Adult Treatment Panel III). JAMA 28: 486- 2497.

23. National Cholesterol Education Panel (1991) Report of the Expert Panel on Blood Cholesterol Levels in Children and Adolescents. Bethesda, Md National Institutes of Health: 91-2732.

24. Boney CM, Verma A, Tucker R, Vohr BR (2005) Metabolic syndrome in childhood: association with birth weight, maternal obesity, and gestational diabetes mellitus. Pediatrics 115: e290-296.

25. Alberti KG, Zimmet $P$, Shaw J; IDF Epidemiology Task Force Consensus Group (2005) The metabolic syndrome--a new worldwide definition. Lancet 366: 1059-1062.

26. Vikram NK, Misra A, Pandey RM, Luthra K, Wasir JS, et al. (2006) Heterogeneous phenotypes of insulin resistance and its implications fo defining metabolic syndrome in Asian Indian adolescents. Atherosclerosis 186 193-199.

27. Golley RK, Magarey AM, Steinbeck KS, Baur LA, Daniels LA (2006) Comparison of metabolic syndrome prevalence using six different definitions in overweight pre-pubertal children enrolled in a weight management study. Int $J$ Obes (Lond) 30: 853-860.

28. Friend A, Craig L, Turner S (2013) The prevalence of metabolic syndrome in children: a systematic review of the literature. Metab Syndr Relat Disord 11 71-80.

29. Tailor AM, Peeters PH, Norat T, Vineis $P$, Romaguera D (2010) An update on the prevalence of the metabolic syndrome in children and adolescents. Int $\mathrm{J}$ Pediatr Obes 5: 202-213.

30. de Boo HA, Harding JE (2006) The developmental origins of adult disease (Barker) hypothesis. Aust N Z J Obstet Gynaecol 46: 4-14.

31. Huxley RR, Shiell AW, Law CM (2000) The role of size at birth and postnata catch-up growth in determining systolic blood pressure: a systematic review of the literature. J Hypertens 18: 815-831.

32. Dunger DB, Ahmed ML, Ong KK (2005) Effects of obesity on growth and puberty. Best Pract Res Clin Endocrinol Metab 19: 375-390.

33. Burt Solorzano CM, McCartney CR (2010) Obesity and the pubertal transition in girls and boys. Reproduction 140: 399-410.

34. Morrison JA, Sprecher DL, Biro FM, Apperson-Hansen C, Dipaola LM (2002) Serum testosterone associates with lower high-density lipoprotein cholesterol in black and white males, 10 to 15 years of age, through lowered apolipoprotein $\mathrm{Al}$ and All concentrations. Metabolism 51: 432-437.

35. Misra A, Vikram NK, Sharma R, Basit A (2006) High prevalence of obesity and associated risk factors in urban children in India and Pakistan highlights immediate need to initiate primary prevention program for diabetes and coronary heart disease in schools. Diabetes Res Clin Pract 71: 101-102.

36. Unnikrishnan R, Anjana RM, Mohan V (2014) Diabetes in South Asians: is the phenotype different? Diabetes 63: 53-55.

37. Yajnik CS, Lubree HG, Rege SS, Naik SS, Deshpande JA, et al. (2002) Adiposity and hyperinsulinemia in Indians are present at birth. J Clin Endocrinol Metab 87: 5575-5580. 